\title{
Inhibition and individual differences in behavior and emotional regulation in adolescence
}

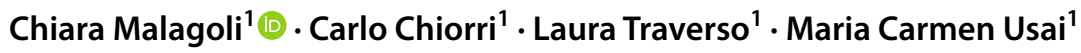

Received: 13 October 2020 / Accepted: 20 July 2021 / Published online: 7 August 2021

(c) The Author(s) 2021

\begin{abstract}
The Impulsivity/Reflexivity issue in inhibitory control ability has seldom been investigated in terms of individual differences in typically developing populations. Although there is evidence of changes in executive functioning (EF), including inhibition, in adolescence, very little is known about the role of individual differences. Using the data from 24014 -to-19-year-old high school students who completed a battery of EF tasks (Flanker, Go No-Go, Antisaccade, and Stop signal task), measures of emotion regulation strategies and behavioral difficulties, we performed a latent profile analysis to identify qualitatively distinct score profiles. The results showed the existence in adolescence of two inhibition profiles, Impulsive $v s$ Reflexive, differing in performances at the inhibition tasks. The two profiles were not associated with socio-demographic characteristics, or to psychological variables, such as behavioral characteristics and emotional regulation strategies.
\end{abstract}

Inhibition is one of the core abilities of Executive Function $(\mathrm{EF})$, a set of top-down processes that allow people to regulate their thoughts and behaviors (Miyake \& Friedman, 2012). Inhibition includes different behavioral and cognitive abilities, such as managing impulses/interferences (Diamond, 2013; Nigg, 2000), and fosters self-regulation also in complex situations.

EFs have a prolonged development over time, from early infancy until late adolescence up to young adulthood (Best \& Miller, 2010; Johnson, 2000, 2001; Luna et al., 2004), and inhibition emerges early, showing a significant peak of development in preschool age (see e.g., Best \& Miller, 2010). Changes in their latent organization also occur early on in development and separated inhibitory dimensions, such as the ability to stop a prepotent response and the ability to suppress the stimuli interference, can be already observed at age 3 (Gandolfi et al., 2014). This structure appears to be

Chiara Malagoli

chiaramalagoli.dr@gmail.com

Carlo Chiorri

carlo.chiorri@unige.it

Laura Traverso

lauratraverso4@gmail.com

Maria Carmen Usai

maria.carmen.usai@unige.it

1 Department of Education, University of Genoa, C.so Andrea Podestà 2, 16128 Genova, Italy stable during childhood (Traverso et al., 2018) and adulthood (Rey-Mermet et al., 2017). Changes in the EF domain are well documented also in adolescence (Cragg \& Nation, 2008; Crone et al., 2006; Huizinga et al., 2006; Michel \& Anderson, 2009), but very little is known about the existence of different profiles in terms of inhibitory efficiency and how they may be related to other cognitive and emotional domains between age 14 and 19. Since during adolescence a tendency toward impulsiveness and risk-taking/sensation seeking (Dahl, 2004) co-occur with biologically based changes of ER, and a lack of control has been associated with maladaptive and dangerous behaviors (substance use and gambling, Vitaro et al., 1998; internet addiction, Cao et al., 2007; earlier onset of alcohol-use, Soloff et al., 2010), evidence of different profiles in inhibition in adolescence can be of paramount importance for understanding development. More specifically, it seems necessary to investigate whether it is possible to distinguish diverse inhibitory profiles in adolescence and to test whether these differences in inhibitory skills are related to emotional and behavioral difficulties.

\section{Inhibition and individual differences}

The lack of control in inhibition has recently been theorized as a distinctive pattern of behavior (DeYoung, 2010). Nevertheless, very little is known about the development of specific individual profiles of inhibition in typical development. 
To the best of our knowledge, very few studies have investigated the existence of different profiles in cognitive inhibition. Some research about behavioral inhibition, see the "Dual Process" theorization in decision making (e.g., Evans \& St, 2003), has been carried out, and focused on the neurobiological bases of environmental and social interactions, together with resource management in complex situations. However, little is known about the possibility to profile core cognitive abilities that are specific components of the general construct of inhibition, such as response inhibition (e.g., the ability withhold a response), interference control (e.g., the ability to manage distracting or interferent stimuli), oculomotor inhibition (e.g., execute a subdominant response in the face of a more dominant response), and, in general, more specific abilities connected to cognitive and behavioral inhibition (Nigg, 2000). Very few studies have tested the existence of different profiles in terms of Impulsivity $v s$ Reflexivity regarding executive functioning (Haghighi et al., 2015; Quiroga et al., 2007). In particular, Haghighi et al. (2015) investigated tendencies toward Impulsivity/Reflectivity in typical development using the Matching Familiar Figures Test in college students. By analyzing both the balance and the imbalance between accuracy and RTs, the authors found two distinct profiles, supporting the existence of different response control tendencies, impulsive $v s$ reflective.

Schiller et al. (2014) investigated the development of individual differences in inhibitory capacity through an electrophysiological index of response inhibition, the No Go-Anteriorization (NGA; Fallgatter \& Strik, 1999). Their results indicated that higher bilateral baseline activation in the lateral prefrontal cortex (PFC) was associated with a larger NGA, which is a better inhibition response. Although the authors suggested caution in interpreting these results, since the EEG slow waves at rest are complex to interpret, this finding supports the role of PFC in response inhibition. The hypothesis about differences in the baseline of these processes is consistent with the existing behavioral literature (Haghighi et al., 2015; Quiroga et al., 2007).

The recent studies on EFs have suggested that distinct patterns of neuropsychological functioning may exist in both hyperactive/inattentive and healthy adolescents and young adults (Gomez et al., 2014; Rau et al., 2016). Specifically, these studies hypothesized that homogenous subgroups of participants could be identified on the basis of patterns in the performance of a set of EF tests (e.g., Gomez et al., 2014). Rau et al. (2016) observed three distinct profiles characterized by (i) average EF performances, (ii) set maintenance weakness under nonverbal conditions, and (iii) weaknesses in cognitive flexibility combined with poor executive performance. Quite recently, it has been debated as well whether neuropsychological tests are necessarily a better means for assessing impulsivity than are trait measures, suggesting that cognitive impulsivity might only sometimes be indicative of trait impulsivity, and trait impulsivity might also only sometimes be indicative of cognitive impulsivity, but without a complete overlap (Glicksohn et al., 2016). Glicksohn et al. (2016) proposed to incorporate both self-report and analysis of performance in neuropsychological assessment research, as a solution to such incomplete overlap and the related difficulties in assessing impulsivity. To the best of our knowledge, no similar study has been performed using a variety of inhibitory tasks to investigate different profiles in inhibitory baselines using a person-centred approach.

\section{Inhibition and emotion regulation}

Emotion regulation (ER) can be conceptualized as the ability of controlling and regulating one's emotions (Eisenberg et al., 2010; Mischel \& Ayduk, 2002). According to Diamond (2013), ER is a component of the broader concept of self-regulation and substantially overlaps with inhibitory abilities. Inhibition supports self-regulation even in more emotional conditions and it plays a central role in regulating behavior (Eisenberg et al., 2010; Prencipe et al., 2011). Specifically, response inhibition influences adaptive abilities and self-regulation (Prencipe et al., 2011), and, consistent with these findings, impulsivity has been associated with maladaptive/dangerous behaviors (Cao et al., 2007; McLaughlin et al., 2011; Soloff et al., 2010; Vitaro et al., 1998). In this perspective, being efficient or impulsive as a "baseline" may play a role in differences in the ability to be adaptive despite the emotional arousal.

The role of inhibition in ER was also highlighted by Schweizer et al. (2020), who reviewed the literature on adolescents performing the same cognitive control tasks (Go-No Go or Stroop task) with affective vs. neutral stimuli. Inhibition of affective stimuli was found to display a similar but more protracted time-course linear developmental trajectory with respect to inhibition of neutral stimuli (Tottenham Hare, \& Casey, 2011) or a quadratic effect of development (e.g., Cohen et al., 2016; Somerville et al., 2011), suggesting that inhibition of affective information is reduced during adolescence. The authors also assumed that inhibition of affective information is associated with ER, showing that the use of maladaptive strategies such as rumination can be associated with cognitive control. In particular, adolescents with a strong tendency to rely on rumination showed poorer performance in inhibition to affective stimuli (Hilt et al., 2014, 2017; Romens \& Pollak, 2012). The literature suggests a link between the lack of inhibitory abilities and the presence of difficulties in ER; however it is unclear whether specific individual differences in inhibitory abilities may 
be associated with a difference in the ability to regulate emotions.

\section{Present study}

The first aim of the current study was to identify different profiles of inhibitory efficiency, with a cross-sectional design, in a sample of adolescents using a battery of computerized tasks designed to assess different components of inhibition, such as response inhibition (i.e., the ability to suppress a dominant but inappropriate response and to prevent impulsive behavior), interference control (i.e., the ability to prevent interference due to resource or stimulus competition), and oculomotor inhibition (i.e., the ability to inhibit saccades towards to-be-ignored stimuli, and in this perspective to execute a subdominant response in the face of a more dominant response; Diamond, 2013; Friedman \& Miyake, 2004; Nigg, 2000). The second aim of the study was to investigate whether such profiles of inhibition efficiency were associated with individual differences in ER and behavioral outcomes.

Previous research (Rothbart et al., 2003; Zelazo \& Müller, 2002) has shown a protracted development of inhibition up to late adolescence. Owing to the high sensitivity of EF to the environment (Mezzacappa, 2004; Noble et al., 2005), we expected inhibition to be sensitive to individual differences development, in terms of efficiency, intended in the balance of both speed, measured throughout RTs, and accuracy, and that these differences would emerge even in the typical population (Diamond, 2002; Kochanska et al., 1997). In line with the few studies in this domain (Haghighi et al., 2015; Quiroga et al., 2007), we expect to be able to identify at least two different profiles, among the possible combinations, inefficient, efficient, or reflexive based on the balance or unbalance between accuracy and RTs. In this perspective, we expect more efficient individuals to show higher accuracy and relatively low RTs, while less efficient individuals should show the opposite tendency registering low accuracy with low RTs, whereas reflexive individuals would register high accuracy but also higher RTs. We also expect that possibly different profiles of functioning could be differentially associated with selfreported difficulties in ER and behavioral problems, since (i) the ability to use inhibitory abilities plays a role in the regulation of thoughts and feelings (e.g., Rothbart et al., 2007), as individuals need to flexibly attend to environmental stimuli and plan effective coping strategies, and (ii) difficulties with effortful control, including inhibition, have been linked to internalizing problems (e.g., Eisenberg et al., 2001).

To examine profiles of inhibition in adolescence, we administered tasks that test the ability to manage visual interference, to inhibit an automatic response, to stop an ongoing response (in both neutral and emotional conditions), and to inhibit eye movement. These tasks are common and well-established measures of different abilities connected to inhibition (Miyake \& Friedman, 2012; Miyake et al., 2000). In addition, we asked participants to complete two self-report measures of difficulties in ER and behavior, to test their association with profile membership. This is a secondary data analysis as the data considered in the present study are part of a larger cross-sectional study aimed to investigate the latent organization of EF and the possible impact on ER in adolescence (see Malagoli 2018a, b).

\section{Method}

\section{Participants}

A convenience sample of 240 (158 females) 14-to-19-yearold high school Italian students participated in this study. Participants were recruited from 33 classes at 5 public schools and belonged to the middle class. The student's participation in the study was voluntary, recruitment was organized at school, prior to the presentation of the study to the classes. Informed, written consent was obtained from school principals, participants' parents, and the participants themselves before data collection. Participants were excluded if Italian was not their first language or if they had been diagnosed with any disease or neurological/mental disorder. On the basis of the information provided by the school and by the participants throughout the youth self-report (YSR, 11-18 years, Achenbach \& Rescorla, 2001), four participants were excluded for Italian not being their first language, eight due to learning disabilities, and one due to neurological issues. The final sample included 227 participants (148 females; mean age:16.9 years, SD: 18.57 months).

\section{Materials and procedure}

A battery of inhibitory tasks was administered during two individual sessions that lasted approximately $45 \mathrm{~min}$ each, in a quiet room provided by the school. The participants were also asked to fill two self-reports measuring maladaptive outcomes and ER difficulties.

\section{Inhibition tasks}

Flanker task (Eriksen \& Eriksen, 1974) This task assesses the ability to manage visual interference and requires a fast response to a centrally presented target stimulus, in this case arrows pointing left or right, flanked by several distractor stimuli (arrows or horizontal bars) that can activate conflict 
responses. Congruent, incongruent, and neutral trials were shown. The task comprised a practice block of six trials and a test block of 48 trials ( 16 trials for each condition).

Go-No Go (Donders, 1969) The Go-No Go is designed to assess the ability to stop an automatic response. The task requires participants to press a button when a given figure target (a blue square) is displayed and to refrain from pressing if any other figure (a blue rectangle) is displayed ( $20 \%$ of the stimuli). Participants practiced on 20 trials and then received 100 target trials. Feedback was provided for every answer. The stimulus duration time was $1500 \mathrm{~ms}$.

Stop signal task (Logan, 1994) This task aimed to measure response inhibition (Lappin \& Eriksen, 1966). It consisted of a practice phase of 32 trials and an experimental phase of three blocks of 64 trials. Each trial started with the presentation of a fixation sign, which was replaced by the primary task (an arrow pointing left or right) stimulus after $250 \mathrm{~ms}$. The stimulus remained on the screen until the participant responded or $1250 \mathrm{~ms}$ had elapsed. The default interval between stimuli was fixed to $2000 \mathrm{~ms}$. During "stop" trials, a signal was presented after a variable Stop Signal Delay (SSD). Participants were informed that the signal would be delayed if they slowed down their responses to wait for the signal.

Antisaccade task (adapted from Roberts et al., 1994) This task is a common measure of oculomotor inhibition. A fixation point appeared in the middle of the computer screen for a variable amount of time. A visual cue (a black square) then appeared on one side of the screen for $175 \mathrm{~ms}$, followed by the target stimulus (an arrow inside of an open square) on the opposite side for $150 \mathrm{~ms}$. The target was then masked until the participant pressed a button to indicate the direction of the target or until $1250 \mathrm{~ms}$ had elapsed. Participants practiced on 22 trials and then received 90 target trials.

Emotional Go-No Go task (Hare et al., 2005) This type of Go-No Go was meant to measure the inhibition of an automatic response in a more emotional condition. The set of stimuli consists of grayscale images of 10 adults (five males; Ekman \& Friesen, 1976) showing three different expressions (happy, fearful, and calm/neutral). Face stimuli were presented individually in the center of the screen. Participants were instructed to press the spacebar as fast as they could when the named expression was presented and to refrain from doing so in the "no-go" condition ( $30 \%$ of trials). The test comprised 6 randomized blocks, counterbalanced for each emotion and neutral face with 50 randomized trials for each condition. In each block, only two target emotional stimuli are presented, one in the "go" condition and one in the "no-go" condition. Stimulus duration was $500 \mathrm{~ms}$, with $1000 \mathrm{~ms}$ between trials. Practice trials were administered.

Cronbach's alphas for all these tasks ranged from 0.39 and 0.85 (see Table 1). For all tasks, the measures considered in this study were accuracy and reaction times (RTs). Regarding the Stop signal task, we decided to not use the general index for efficiency, the SSRT (the Stop Signal Reaction Time) which provides the estimation of the covert latency of the stop process and which we did use in a previous study (Malagoli 2018a) meant to investigate the latent components of inhibition and Working Memory (WM) in adolescence. This choice relies on the characteristics of the Stop signal task paradigm that throughout the SSRT offers a more global measure of inhibitory efficiency while throughout the RT measured in the no-stop (go) condition accounts for an increased variability (Matzke, Verbruggen \& Logan, 2019) allowing us to take more into account possible differences in the baseline of inhibitory processes.

\section{Self-report measures}

Youth self-report (YSR, 11-18 years, Achenbach \& Rescorla, 2001 Italian version as available on the http://www.aseba. org website). The YSR is part of the Achenbach System of Empirically Based Assessments (ASEBA). It provides an assessment of the respondent's social and emotional functioning. The 2001 revised YSR comprises 112 problem items and provides scores in eight subscales (Anxious/Depressed, Withdrawn/Depressed, Somatic Complaints, Social Problems, Thought Problems, Attention Problems, Rule-Breaking Behavior, and Aggressive Behavior). Cronbach's alphas were larger than 0.70 for all scales, and are reported in Table 1.

Difficulties in Emotion Regulation Scale (DERS, Gratz \& Roemer, 2004 Italian version in Giromini et al., 2012). The DERS is a 36-item, self-report measure developed to assess clinically relevant difficulties in ER. Items provide scores on six scales (Nonacceptance, Goals, Impulse; Awareness; Strategies; Clarity).

Cronbach's alphas were computed for the total DERS score and for each subscale, and were all larger than 0.70 (Table 1). More details about the method and the instruments are provided in Sect. 1 of the Supplementary Materials (SM).

\section{Statistical Analysis}

Descriptive statistics and zero-order (Pearson) correlations among measures were computed. Outlier values (i.e., more than three standard deviations from the mean) were excluded. Total excluded values represented $0.62 \%$ of the data. 


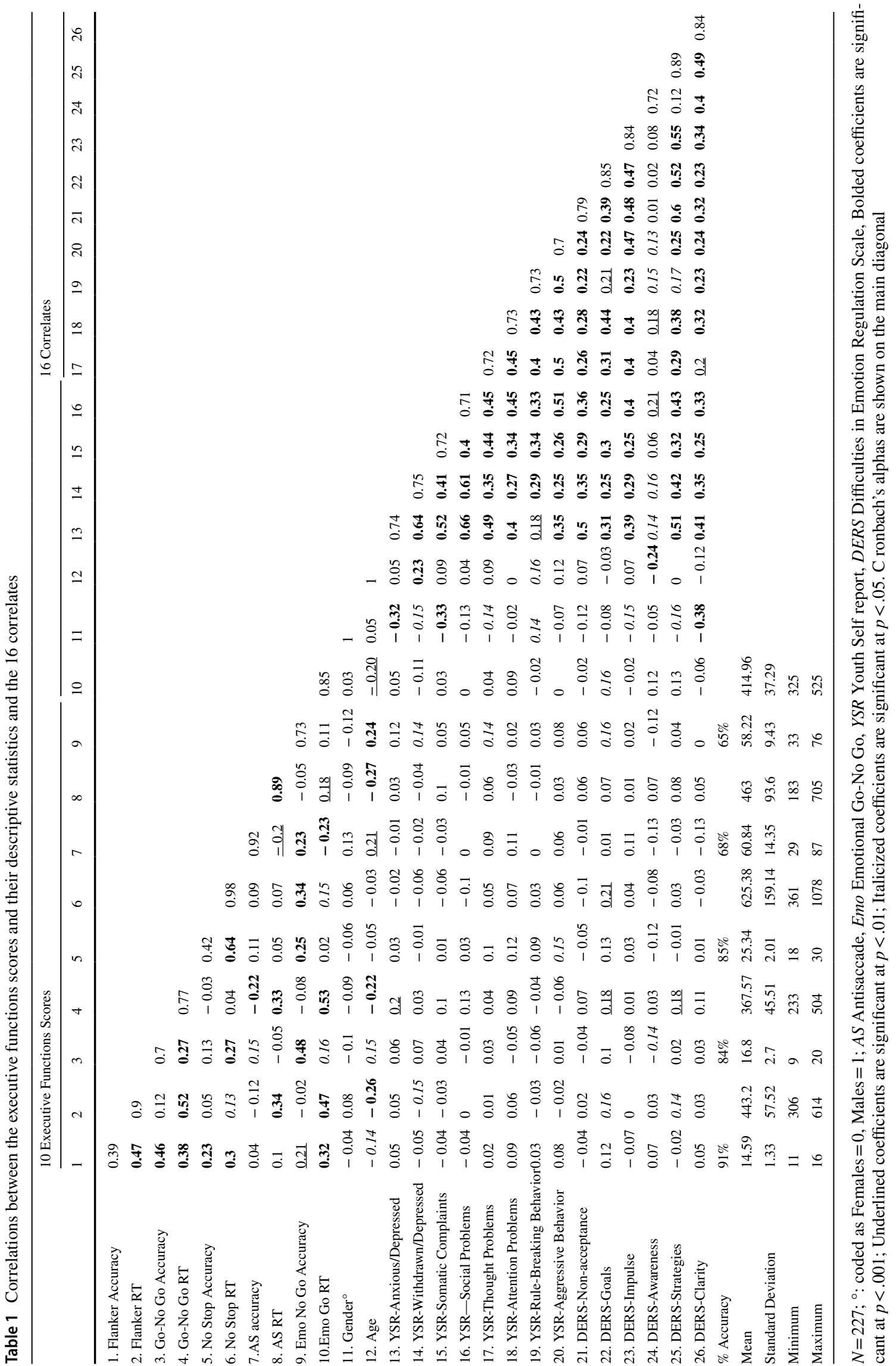


We then used latent profile analysis (LPA) to identify groups of individuals with qualitatively (profile shape) and/or quantitatively (profile level) distinct patterns on EF tasks, and to investigate the association of group membership with a diverse set of correlates (gender, age, behavioral, and emotional problems, and difficulties in ER). LPA is a person-centered approach that focuses on relations among individuals to sort them into groups in which they are similar to each other and different from those in other groups (Lubke \& Muthén, 2005; Pastor et al., 2007). More details on this method are provided in Sect. 2 of the Supplementary Materials (SM).

LPAs were conducted with Mplus (version 7.0; Muthén \& Muthén, 2012) using the TYPE $=$ MIXTURE COMPLEX option to take into account the nesting of participants into classrooms. In subsequent analyses, we included the set of correlates using the 3-step auxiliary variable approach in Mplus (Asparouhov \& Muthén, 2014). Following this approach, in the first step a latent profile model is estimated using only latent profile indicator variables. In the second step, the most likely class variable is created using the latent class posterior distribution obtained during the first step. In the third step, the most likely class is regressed on the predictor variables, taking into account the misclassification in the second step (Asparouhov \& Muthén, 2014). Missing values were handled using the Full Information Maximum Likelihood procedure implemented in Mplus 7.0.

\section{Results}

Descriptive statistics and correlations are reported in Table 1. With regard to DERS scores, considering all the 6 subscales, none of the participants presented scores above the score that is considered the threshold for clinical risk for all the 6 subscales and only $1.3 \%$ of participants presented scores above the threshold for one to two scales. Regarding YSR, considering all 8 subscales, $48 \%$ of participants scored above the threshold in at least one scale, none of the participants reported scores above the threshold in all the 8 scales and only $6.6 \%$ of participants reported scores above the threshold for 4 or more subscales.

Performance in inhibition tasks did not differ between genders (see correlations with gender in Table 1 and Sect. 4 of the Supplementary Materials); age was significantly associated, albeit weakly ( $r$ s $<1.30 l$ ), with slower RTs and higher accuracy. The inhibitory tasks were associated with each other, consistent with previous findings. Significant correlations were also found for self-report measures, while only a few weak correlations were found between EF and self-report measures $(|.18|<\mathrm{rs}<\mathrm{l} .27 \mathrm{l})$. Notably, the RTs on the Go-No Go task were positively associated with YSRAnxious/Depressed, DERS-Difficulties in Engaging in Goal Directed Behavior, and DERS-Limited Access to ER Strategies. DERS-Difficulties in Engaging in Goal Directed Behavior were also positively correlated with RTs on the Stop signal task.

Results of the LPA are reported in Table 2. For the three information indices (AIC, BIC, and SSA-BIC), the values continued to decrease across the range of models considered, apparently suggesting that we should consider at least eight groups. None of the models resulted in groups with less than $1 \%$ of the cases, whereas models positing more than five groups each resulted in at least one group with less than $5 \%$ of the cases. The results based on the significance tests (see SM) were very similar to each other, and they converged in suggesting that the appropriate number of groups was two (Class 1 size: 58; Class 2 size: 169). We thus used the Mplus MODEL CONSTRAINT option to specify class mean score comparisons for each of the measures used to perform the LPA. After adjustment for multiple comparisons performed with the adaptive Benjamini and Hochberg (2000) step-up false discovery rate-controlling procedure, all comparisons revealed that participants in the larger class obtained significantly higher scores than their
Table 2 Goodness of fit for Latent Profile Models Based on Different Numbers of Groups

\begin{tabular}{llllllll}
\hline $\begin{array}{l}\text { No } \\
\text { Groups }\end{array}$ & $\begin{array}{l}\text { No } \\
\text { Parm }\end{array}$ & AIC & BIC & SSA-BIC & p LMR (BLRT) & $\begin{array}{l}\text { Smallest Group } \\
\text { Size (Percentage) }\end{array}$ & Entropy \\
\hline 1 & 20 & 6301.505 & 6370.004 & 6306.618 & - & - & - \\
2 & 31 & 6096.028 & 6202.202 & 6103.954 & $.0328(.0348)$ & $58(26 \%)$ & 0.808 \\
3 & 42 & 5946.999 & 6090.847 & 5957.737 & $.1222(.1258)$ & $60(26 \%)$ & 0.818 \\
4 & 53 & 5867.885 & 6049.407 & 5881.435 & $.2965(.3018)$ & $40(18 \%)$ & 0.819 \\
5 & 64 & 5830.078 & 6019.275 & 5846.440 & $.6087(.6125)$ & $13(6 \%)$ & 0.853 \\
6 & 75 & 5808.529 & 5995.401 & 5827.705 & $.5305(.5325)$ & $7(3 \%)$ & 0.865 \\
7 & 86 & 5784.160 & 5973.706 & 5806.147 & $.6677(.6687)$ & $10(4 \%)$ & 0.863 \\
8 & 97 & 5772.040 & 5962.260 & 5796.840 & $.6211(.6221)$ & $7(3 \%)$ & 0.876 \\
\hline
\end{tabular}

No number, Parm parameters, AIC Akaike's Information Criterion, BIC Bayesian Information Criterion, $S S A-B I C$ sample-size adjusted Bayesian Information Criterion, $p L M R(B L R T) \mathrm{p}$ values for the Lo-Mendell-Rubin likelihood and the bootstrap likelihood ratio test for $K$ versus $K-1$ classes. $N=227$ 
Fig. 1 Profiles of EF task scores based on latent profiles. $R T$ reaction time, $A S$ Antisaccade, Emo Emotional Go-No Go; *** $p<.001 ; * *: p<.01 ; *: p<.05$

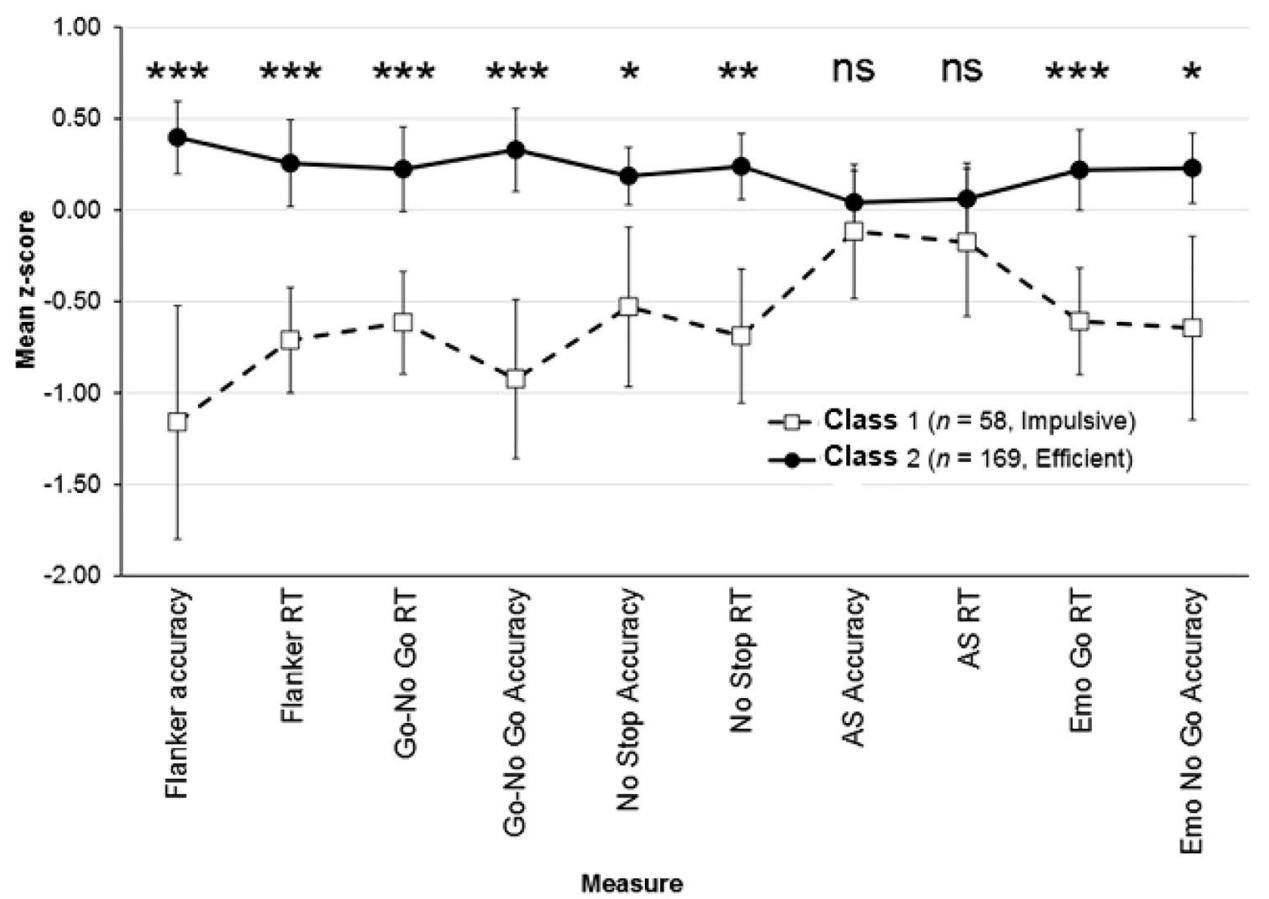

counterparts in the smaller class in all tasks, except in the Antisaccade task (Fig. 1). Class 1 participants showed a general impulsive tendency in all tasks, and this was reflected in a worse performance in terms of accuracy. For this reason, we labeled it "Impulsive". Conversely, Class 2 participants showed a good performance on the majority of tasks, with high accuracy scores and quite low
RTs. We therefore labeled it "Reflexive". When we used the 3-step method for latent class predictor variables, we found that none of the predictors was significantly associated with class membership, with very small odds ratios (Table 3). Evidence of the replicability of the obtained classes was obtained by drawing 500 random samples of 170 participants ( $75 \%$ of the original sample) and
Table 3 Association of the two latent classes (reference: class 2) to the correlates (auxiliary) variables

\begin{tabular}{lccc}
\hline Predictor & Estimate & SE & $p$ \\
\hline Age & 0.26 & 0.27 & .336 \\
Gender & -0.26 & 0.57 & .641 \\
YSR-Anxious/Depressed & -0.15 & 0.08 & .055 \\
YSR-Withdrawn/Depressed & 0.08 & 0.16 & .632 \\
YSR-Somatic Complaints & 0.04 & 0.10 & .650 \\
YSR-Social Problems & 0.17 & 0.19 & .393 \\
YSR-Thought Problems & -0.10 & 0.10 & .302 \\
YSR-Attention Problems & -0.06 & 0.11 & .622 \\
YSR-Rule-Breaking Behavior & -0.05 & 0.09 & .560 \\
YSR-Aggressive Behavior & -0.04 & 0.10 & .692 \\
DERS-Non-acceptance & 0.36 & 0.33 & .276 \\
DERS-Goals & -0.72 & 0.59 & .225 \\
DERS-Impulse & 0.66 & 0.43 & .127 \\
DERS-Awareness & -0.11 & 0.33 & .738 \\
DERS-Strategies & -0.22 & 0.41 & .584 \\
DERS-Clarity & 0.12 & 0.43 & .785 \\
\hline
\end{tabular}

SE standard error, YSR Youth Self Report, DERS Difficulties in Emotion Regulation Scale. P-values are not corrected for multiple comparisons. When the Benjamini-Hochberg procedure was applied, the significance level of all the estimates was .784 
performing the same analyses of the manuscript on each of them. The details of the analyses and the results are reported in the supplementary materials.

\section{Discussion}

In this study, we investigated whether different profiles in scores on inhibition tasks exist and whether they are associated with difficulties in ER and adaptive behavior skills. The results showed that inhibition tasks are associated with each other, suggesting that these abilities are actually tightly connected (Friedman \& Miyake, 2004). We did not find gender differences in inhibition tasks performance, while the association with age, with older adolescents showing slower RTs and higher accuracy, is consistent with previous studies and indicates a development in inhibitory abilities during adolescence (e.g., Diamond, 2013; Nigg, 2000). Scores on self-report measures of ER and emotional/behavioral problems were also significantly associated. This result is consistent with the findings presented by Kaufman et al. (2015) who found that scores on the DERS were significantly associated with scores on the YSR, and in general with the existing literature that addresses how emotion (dys)regulation indicators may be considered an indicator for vulnerabilities across diagnoses (e.g., Beauchaine \& Thayer, 2015).

We found weak but significant positive bivariate associations of RTs to inhibitory tasks, such as the Go-No Go and the Stop signal Task, with measures of anxiety/depression, difficulties in engaging in goal-directed behavior, and limited access to ER strategies. This result is consistent with the previous results (Lopez-Vergara \& Colder, 2013), as individual differences in reaction to aversive stimuli can lead to dysregulated impulsive behavior and individuals who are highly sensitive to punishment, in fact, seem to have an attentional bias to certain emotional cues (Wallace et al., 1991).

The main aim of this paper was to investigate whether individual profiles of inhibitory efficiency, assessed throughout a specific selection of inhibitory tasks accounting, could be distinguished. Using LPA, we found two different profiles of inhibitory control abilities that differed in terms of accuracy and RTs on EF tasks. Participants in the latent class labeled as Impulsive showed a general tendency to respond fast in all tasks, with worse performances in terms of accuracy. Reflexive participants showed a good inhibitory control performance both in terms of speed and accuracy, with a good performance on the majority of tasks, with relatively high accuracy scores and relatively low RTs. In everyday life, being reflexive means being able to process stimuli at a speed that also allows for accuracy. These results are consistent with the limited existing literature about differences in profiling of inhibition development that suggest the existence of particularities at this level (Schiller et al., 2014) and indicate that it is actually possible to identify profiles of functioning that differ in inhibitory efficiency (Haghighi et al., 2015; Quiroga, et al., 2007).

No differences in the performance on the Antisaccade task were found between the two classes. As a possible explanation, it should be noted that this task involves the automatic control of eye movements. In fact, the Antisaccade task requires at least two processes: the suppression of a reflexive prosaccade toward the stimulus and the generation of the antisaccade away from the stimulus to an empty location, that involve oculomotor processes (Nigg, 2000). It is unclear whether the same brain systems involved in the inhibition of eye movements are also engaged in the inhibition of other behaviors. These characteristics may explain the lack of difference in performance between the two classes on this specific task.

It is important to point out that the classes we identified in this study reflect different profiles that participants exhibited in the specific inhibitory tasks we chose for the study. In other words, this may not reflect impulsiveness or reflectiveness in other general domains, as the goal of the study was a more precise investigation about individual differences in inhibitory control on a cognitive level. Nevertheless, to the best of our knowledge, this is the first study showing that different profiles of inhibitory efficiency can be distinguished in adolescents.

The results of this study add to the existing literature as they show that it is actually possible to distinguish different profiles in the cognitive ability to inhibit responses, as these baselines in individual differences may be proper characteristics of individuals, even in adolescence. Studies with adults have already shown the existence of different characteristics in terms of impulsivity $v s$ reflexivity (Giedd, 2010; Giedd et al., 2008) in the general population, but what was missing was an investigation on previous stages of development. The results of this study support this evidence and add knowledge about a less investigated stage in development.

When we regressed class membership on gender, age, and scores on measures of ER and behavioral difficulties, we found no significant results. This outcome did not support our hypothesis that different styles of inhibition correspond to more difficulties or at least to a weakness in these domains, indeed bivariate correlations indicated that performance on inhibitory tasks and scores on self-report measures were partially (weakly) correlated. A similar pattern of results also emerged in a study by Romer et al. (2009) that analyzed EF and impulsivity as correlates of risk taking and problem behavior in preadolescents. In this study, too, YSR scores showed no relation with more cognitive aspects. The specificity of the abilities considered in the study should be taken into consideration. Some aspects of behavioral impulsivity may be instantly realized in everyday life, since 
individuals can experience the immediate consequences of them, while emotions may need the ability to mentalize feelings through deep introspection to be fully understood. As mentioned above, this ability in adolescence is still developing (Keulers et al., 2010). In fact, while computerized tasks are direct instruments, to accurately answer self-reports (especially those concerning ER), participants must possess self-awareness about existing difficulties, together with being able to evocate specific situations. Interestingly, the most recent literature on the topic suggested that questionnaire measures of self-control and performance measures of inhibition and related EF are largely unrelated to each other (Paap et al., 2020; Saunders, Milyavskaya, Etz, Randles \& Inzlicht, 2020). However, Sanders et al., (2020) made clear that they do not claim that their results would invalidate one measure or the other. Rather, they argue that their results suggest that inhibitory tasks, such as the Stroop and Flanker tasks, "do not reflect the broader individual difference construct that is reflected in self-report scales, and, equally, that scores on the self-control scale are not analogous to the processes assessed by the Stroop and flanker tasks" (p. 11).

More generally, previous studies reported low correlations between direct and indirect measures of EF (Toplak et al., 2013) and even EF training studies report that EF improvements struggle to generalize to other cognitive and behavioral domains (Diamond \& Ling, 2016). In general, studies that attempted to measure these components using direct and indirect measures reported nonsignificant correlations between inhibition tasks and self-report measures of impulsivity (Eisenberg et al., 2019; Nęcka et al., 2018; Stahl et al., 2013) and conscientiousness (Fleming et al., 2016).

It should be considered that diverse behavioral outcomes may be associated with different EF components. In this regard, previous studies considering typical and atypical development showed that in understanding the relation between these cognitive abilities and functional profiles, a distinction should be considered between the cool and hot aspects of EF (Campbell \& Von Stauffenberg, 2009). Whereas cool EF is more likely to be involved in relatively abstract, decontextualized problems, hot EF tasks require the regulation of affect and motivation (Zelazo \& Müller, 2002). This latter aspect, namely, affective control, can be more associated with ER than cool measures of inhibition (Schweizer et al., 2020). In the current study, mainly performances on cool inhibition tasks were examined, which may be less associated with social and emotional outcomes than hot EF task performance.

A different perspective on this result may also rely on an adaptive role that the ability to react fast may play in certain cases (e.g., running away before getting into a fight). In these cases, being fast could be more important than being accurate. The YRS and the DERS questionnaires indirectly investigate, respectively, social aspects of regulation, like the tendency to "lose control"/ "get into a fight"/break the rules", and emotional aspects of regulation, as in the case of DERS-Impulse scale, assessing difficulties in controlling one's behavior "when feeling upset" which are specific social aspects at one extreme of impulsivity. However, being impulsive may not be necessarily linked to extreme behaviors, since it may be modulated as an inner "rhythm" of the individual. In this perspective, being impulsive may not be a risk factor per se. It may depend on the task/situation, so that being impulsive may not lead to extreme outcomes but simply be a baseline, which needs to be really pushed to the extreme and cooccur with other factors to become a risk factor (Soloff et al., 2010; Vitaro et al., 1998).

A few limitations of this study warrant mention. First, since we used convenience sampling, our sample cannot be considered fully representative of the adolescent population. Consequently, the results might be of limited generalizability, e.g., because of the noise due to the sociodemographic variation that cannot be controlled (see e.g., Bornstein et al., 2013). Convenience sampling is known to provide insufficient power to detect differences among sociodemographic subgroups, and this might be another reason why we did not find statistically significant associations of profile membership with gender and age. Second, since correlations between test scores are attenuated by different methods other than measurement error, the lack of association of profile membership with measures of ER and behavioral difficulties could also be explained by a lack of power. Future studies are thus invited to enrol larger and more representative samples, possibly also involving clinical samples, in order to address and investigate further these issues while also considering noncluster-based methods to approach similar data.

The third limitation is the relatively low reliability of accuracy scores for the Flanker and the Stop signal tasks, but this is an issue often reported for executive tasks (Denckla, 1996; Miyake et al., 2000), especially for inhibition ones (Friedman \& Miyake, 2004). Finally, the two profiles were not validated against a noncomputerized task, to investigate whether the use of a computerized task could bias the results of the LPA. Further research is thus needed to shed light on this issue. A fourth limitation is that in the present study adaptive behavioral skills have not been investigated throughout ecological and direct measures, yet only assessed throughout self-report measures. Future studies are; thus, invited to include also specific measures to explore deeper this topic.

Despite these limitations, the study contributes in adding knowledge about the existence of individual differences considering the trajectory of a core cognitive ability as inhibition in a challenging developmental period. The presented results also have important practical implications by suggesting that the impulsive and reflexive profiles are 
not necessarily associated with maladaptive behaviors or ER problems when the continuum of individual differences is considered. Therefore, extreme profiles showing behavioral and emotional problems could be considered qualitatively different from the intermediate profiles, such as those found in the present study (see, e.g., Kagan, 2013).

The present results also suggest important practical implications for teaching and in general for the educational fieldwork. Accounting for individual differences explicitly working towards the strengthening of inhibitory related skills (e.g., structuring differently the learning environment, challenging peer education) or proactively supporting students in the application of strategic learning behaviors or activities, may have a crucial role in fostering students' ability to be efficient in inhibitory related skills while becoming more strategic and proficient in learning.

\section{Conclusions}

The results of this study suggest the existence of specific individual differences in terms of inhibitory efficiency, as two distinct classes that show different profiles in inhibition functioning could be identified: a reflexive and an impulsive one. Class membership was not related to measures of ER or behavioral difficulties, gender, or age, suggesting that, possibly and in line with the most recent literature on the topic, measures of inhibitory control and self-reported measures of self-control and/or impulsivity and consequently appear to be measuring different constructs.

Supplementary Information The online version contains supplementary material available at https://doi.org/10.1007/s00426-021-01565-8.

Funding Open access funding provided by Università degli Studi di Genova within the CRUI-CARE Agreement. This work was supported by a doctoral grant and a research fellowship awarded to the first author by the University of Genoa.

\section{Declarations}

Conflict of interest The authors declare that they have no conflict of interest.

Ethical approval All procedures performed in this study involving human participants were in accordance with the ethical standards of the institutional and national research committee (Ethical Code of Italian Psychology Order and the Ethical Guidelines of the Italian Association of Psychology) and with the 1964 Helsinki declaration and its later amendments. At the time we collected the data no ethical committee was yet present to which we could refer to in our organization. Informed written consent was obtained from the participants or their parents if they were minor before data collection.

Open Access This article is licensed under a Creative Commons Attribution 4.0 International License, which permits use, sharing, adaptation, distribution and reproduction in any medium or format, as long as you give appropriate credit to the original author(s) and the source, provide a link to the Creative Commons licence, and indicate if changes were made. The images or other third party material in this article are included in the article's Creative Commons licence, unless indicated otherwise in a credit line to the material. If material is not included in the article's Creative Commons licence and your intended use is not permitted by statutory regulation or exceeds the permitted use, you will need to obtain permission directly from the copyright holder. To view a copy of this licence, visit http://creativecommons. org/licenses/by/4.0/.

\section{References}

Achenbach, T., \& Rescorla, L. (2001). The manual for the ASEBA school-age forms \& profiles. University of Vermont, Research Center for Children, Youth, and Families.

Asparouhov, T., \& Muthén, B. (2014). Auxiliary variables in mixture modeling: Three-step approaches using Mplus. Structural Equation Modeling, 21(3), 329-341. https://doi.org/10.1080/10705511. 2014.915181

Beauchaine, T. P., \& Thayer, J. F. (2015). Heart rate variability as a transdiagnostic biomarker of psychopathology. International Journal of Psychophysiology, 98, 338-350. https://doi.org/10. 1016/j.ijpsycho.2015.08.004

Benjamini, Y., \& Hochberg, Y. (2000). On the adaptive control of the false discovery rate in multiple testing with independent statistics. Journal of Educational and Behavioral Statistics, 25(1), 60-83. https://doi.org/10.3102/10769986025001060

Best, J. R., \& Miller, P. H. (2010). A developmental perspective on executive function. Child Development, 81(6), 1641-1660. https:// doi.org/10.1111/j.1467-8624.2010.01499.x

Bornstein, M. H., Jager, J., \& Putnick, D. L. (2013). Sampling in developmental science: Situations, shortcomings, solutions, and standards. Developmental Review, 33(4), 357-370. https://doi.org/10. 1016/j.dr.2013.08.003

Campbell, S. B., \& Von Stauffenberg, C. (2009). Delay and inhibition as early predictors of ADHD symptoms in third grade. Journal of Abnormal Child Psychology, 37(1), 1-15. https://doi.org/10. 1007/s10802-008-9270-4

Cao, F., Su, L., Liu, T., \& Gao, X. (2007). The relationship between impulsivity and internet addiction in a sample of Chinese adolescents. European Psychiatry, 22(7), 466-471.

Cohen, A. O., Breiner, K., Steinberg, L., Bonnie, R. J., Scott, E. S., Taylor-Thompson, K. A., \& Casey, B. J. (2016). When is an adolescent an adult? Assessing cognitive control in emotional and nonemotional contexts. Psychological Science, 27, 549-562. https://doi.org/10.1177/0956797615627625

Cragg, L., \& Nation, K. (2008). Go or no-go? Developmental improvements in the efficiency of response inhibition in mid-childhood. Developmental Science, 11(6), 819-827.

Crone, E. A., Bunge, S. A., Van der Molen, M. W., \& Ridderinkhof, K. R. (2006). Switching between tasks and responses: A developmental study. Developmental Science, 9, 278-287. https://doi. org/10.1111/j.1467-7687.2006.00490.x

Dahl, R. E. (2004). Adolescent brain development: A period of vulnerability and opportunities. Annals of the New York Academy of Science, 1021, 1-22. https://doi.org/10.1196/annals.1308.001

Denckla, M. B. (1996). A theory and model of executive function: A neuropsychological perspective. In G. R. Lyon \& N. A. Krasnegor (Eds.), Attention, memory, and executive function (pp. 263-278). Paul H Brookes Publishing. 
DeYoung, C. G. (2010). Impulsivity as a personality trait. In K. D. Vohs \& R. F. Baumeister (Eds.), Handbook of Self-Regulation: Research, Theory, and Applications (2nd ed., pp. 485-502). Guilford Press.

Diamond, A. (2002). Normal development of prefrontal cortex from birth to young adulthood: Cognitive functions, anatomy, and biochemistry. In D. T. Stuss \& R. T. Knight (Eds.), Principles of frontal lobe function (pp. 466-503). New York NY US: Oxford University Press.

Diamond, A. (2013). Executive functions. Annual Review of Psychology, 64, 135-168. https://doi.org/10.1146/annur ev-psych-113011-143750

Diamond, A., \& Ling, D. S. (2016). Conclusions about interventions, programs, and approaches for improving executive functions that appear justified and those that, despite much hype, do not. Developmental Cognitive Neuroscience, 18, 34-48. https://doi.org/10. 1016/j.den.2015.11.005

Donders, F. C. (1969). On the speed of mental processes. Acta Psychologica, 30(412-431), 1868.

Eisenberg, I. W., Bissett, P. G., Zeynep Enkavi, A., Li, J., MacKinnon, D. P., Marsch, L. A., \& Poldrack, R. A. (2019). Uncovering the structure of self-regulation through data-driven ontology discovery. Nature Communications, 10(1), 2319. https://doi.org/ 10.1038/s41467-019-10301-1

Eisenberg, N., Spinrad, T. L., \& Eggum, N. D. (2010). Emotionrelated self-regulation and its relation to children's maladjustment. Annual Review of Clinical Psychology, 6, 495-525. https://doi.org/10.1146/annurev.clinpsy.121208.131208

Eisenberg, N., Cumberland, A., Spinrad, T. L., Fabes, R., Shepard, S., Reiser, M., \& Guthrie, I. K. (2001). The relations of regulation and emotionality to children's externalizing and internalizing problem behavior. Child Development, 72, 1112-1134. https://doi.org/10.1111/1467-8624.00337

Ekman, P., \& Friesen, W. V. (1976). Measuring facial movement. Environmental Psychology and Nonverbal Behavior, 1(1), 56-75. https://doi.org/10.1007/BF01115465

Eriksen, B. A., \& Eriksen, C. W. (1974). Effects of noise letters upon the identification of a target letter in a non search task. Attention, Perception \& Psychophysics, 16(1), 143-149. https://doi. org/10.3758/BF03203267

Evans, J., \& St, B. T. (2003). In two minds: Dual-process accounts of reasoning. Trends in Cognitive Sciences, 7, 454-459. https:// doi.org/10.1016/j.tics.2003.08.012

Fallgatter, A. J., \& Strik, W. K. (1999). The NoGo-anteriorization as a neurophysiological standard-index for cognitive response control. International Journal of Psychophysiology, 32, 233-238. https://doi.org/10.1016/S0167-8760(99)00018-5

Fleming, K. A., Heintzelman, S. J., \& Bartholow, B. D. (2016). Specifying associations between conscientiousness and executive functioning: Mental set shifting, not prepotent response inhibition or working memory updating. Journal of Personality, 84(3), 348-360. https://doi.org/10.1111/jopy.12163

Friedman, N. P., \& Miyake, A. (2004). The relations among inhibition and interference control functions: A latent-variable analysis. Journal of Experimental Psychology: General, 133(1), 101-135. https://doi.org/10.1037/0096-3445.133.1.101

Gandolfi, E., Viterbori, P., Traverso, L., \& Usai, M. C. (2014). Inhibition in toddlers: A latent variable approach. Frontiers in Psychology, 5, 381. https://doi.org/10.3389/fpsyg.2014.00381

Giedd, J. N. (2010). Adolescent brain maturation. In R.E. Tremblay, M. Boivin, \& R.D. V. Peters (Eds.), T. Paus (Topic Ed), Encyclopedia on Early Childhood Development [online]. http:// www.child-encyclopedia.com/brain/according-experts/adole scent-brain-maturation. Accessed May 12, 2018.

Giedd, J. N., Lenroot, R. K., Shaw, P., Lalonde, F., Celano, M., White, S., \& Gogtay, N. (2008). Trajectories of anatomic brain development as a phenotype. Novartis Foundation Symposium, 289, 101-112. https://doi.org/10.1002/9780470751251.ch9

Giromini, L., Velotti, P., de Campora, G., Bonalume, L., \& Zavattini, G. C. (2012). Cultural adaptation of the Difficulties in Emotion Regulation Scale: Reliability and validity of an Italian version. Journal of Clinical Psychology, 68(9), 989-1007. https://doi. org/10.1002/jclp.21876

Glicksohn, J., Hadad, Y., \& Ben-Yaacov, T. (2016). "Now you see me, now you don't": The assessment of impulsivity. Cogent Psychology. https://doi.org/10.1080/23311908.2016.1242682

Gomez, R., Gomez, R. M., Winther, J., \& Vance, A. (2014). Latent profile analysis of working memory performance in a sample of children with ADHD. Journal of Abnormal Child Psychology, 42(8), 1367-1379. https://doi.org/10.1007/s10802-014-9878-5

Gratz, K. L., \& Roemer, L. (2004). Multidimensional assessment of emotion regulation and dysregulation: Development, factor structure, and initial validation of the Difficulties in Emotion Regulation Scale. Journal of Psychopathology and Behavioral Assessment, 26(1), 41-54. https://doi.org/10.1023/B:JOBA. 0000007455.08539 .94

Haghighi, M., Ghanavati, M., \& Rahimi, A. (2015). The role of gender differences in the cognitive style of impulsivity/reflectivity and EFL success. Procedia-Social and Behavioral Sciences, 192, 467-474. https://doi.org/10.1016/j.sbspro.2015.06.072

Hare, T. A., Tottenham, N., Davidson, M. C., Glove, G. H., \& Casey, B. J. (2005). Contributions of amygdala and striatal activity in emotion regulation. Biological Psychiatry, 57(6), 624-632.

Hilt, L. M., Leitzke, B. T., \& Pollak, S. D. (2014). Cognitive control and rumination in youth: The importance of emotion. Journal of Experimental Psychopathology, 5, 302-313. https://doi.org/10. 5127/jep.038113 https://doi.org/10.1016/j.biopsych.2004.12.038

Hilt, L. M., Leitzke, B. T., \& Pollak, S. D. (2017). Can't take my eyes off of you: Eye tracking reveals how ruminating young adolescents get stuck. Journal of Clinical Child and Adolescent Psychology, 46, 858-867. https://doi.org/10.1080/15374416.2015.1121824

Huizinga, M., Dolan, C. V., \& Van der Molen, M. W. (2006). Agerelated change in executive function. Developmental trends and latent variable analysis. Neuropsychologia, 44(1), 2017-2036. https://doi.org/10.1016/j.neuropsychologia.2006.01.010

Johnson, M. H. (2000). Functional brain development in infants: Elements of an interactive specialization framework. Child Development, 71(1), 75-81. https://doi.org/10.1111/1467-8624.00120

Johnson, M. H. (2001). Functional brain development in humans. Nature Reviews Neuroscience, 2(7), 475-483.

Kagan, J. (2013). Temperamental contributions to inhibited and uninhibited profiles. In P. D. Zelazo (Ed.), Oxford library of psychology. The Oxford handbook of developmental psychology, Vol. 2. Self and other (p. 142-164). Oxford University Press.

Kaufman, E. A., Xia, M., Fosco, G., Yaptangco, M., Skidmore, C. R., \& Crowell, S. E. (2015). The difficulties in emotion regulation scale short form (DERS-SF): Validation and replication in adolescent and adult samples. Journal of Psychopathology and Behavioral Assessment. https://doi.org/10.1007/s10862-015-9529-3

Keulers, E. H., Evers, E. A., Stiers, P., \& Jolles, J. (2010). Age, sex, and pubertal phase influence mentalizing about emotions and actions in adolescents. Developmental Neuropsychology, 35(5), 555-569. https://doi.org/10.1080/87565641.2010.494920

Kochanska, G., Murray, K., \& Coy, C. K. (1997). Inhibitory control as a contributor to conscience in childhood: From toddler to early school age. Child Development, 68, 263-277. https://doi.org/10. 2307/1131849

Lappin, J. S., \& Eriksen, C. W. (1966). Use of a delayed signal to stop a visual reaction-time response. Journal of Experimental Psychology, 72(6), 805-811. https://doi.org/10.1037/h0021266

Logan, G. D. (1994). On the ability to inhibit thought and action: A user's guide to the stop signal paradigm. In D. Dagenbach \& T. 
H. Carr (Eds.), Inhibitory processes in attention, memory, and language (pp. 189-239). Academic Press.

Lopez-Vergara, H. I., \& Colder, C. R. (2013). An examination of the specificity of motivation and executive functioning in ADHD symptom-clusters in adolescence. Journal of Pediatric Psychology, 38(10), 1081-1090. https://doi.org/10.1093/jpepsy/jst050

Lubke, G. H., \& Muthén, B. (2005). Investigating population heterogeneity with factor mixture models. Psychological Methods, 10(1), 21-39. https://doi.org/10.1037/1082-989X.10.1.21

Luna, B., Garver, K. E., Urban, T. A., Lazar, N. A., \& Sweeney, J. A. (2004). Maturation of cognitive processes from late to childhood to adulthood. Child Development, 75, 1357-1372. https://doi.org/ 10.1111/j.1467-8624.2004.00745.x

Malagoli C., \& Usai, M. C. (2018a). The effects of gender and age on inhibition and working memory organization in 14- to 19-year-old adolescents and young adults. Cognitive Development, 45, 10-23. https://doi.org/10.1016/j.cogdev.2017.10.005

Malagoli, C., \& Usai, M. C. (2018b). WM in Adolescence: What Is the Relationship With Emotional Regulation and Behavioral Outcomes?. Frontiers in psychology, 9, 844. https://doi.org/10.3389/ fpsyg.2018.00844

Matzke, D., Verbruggen, F. and Logan, G. D. (2019). The Stop-Signal Paradigm. In Stevens' Handbook of Experimental Psychology and Cognitive Neuroscience, J. T. Wixted (Ed.). https://doi.org/10. 1002/9781119170174.epcn510

McLaughlin, K. A., Hatzenbuehler, M. L., Mennin, D. S., \& NolenHoeksema, S. (2011). Emotion dysregulation and adolescent psychopathology: A prospective study. Behaviour Research and Therapy, 49(9), 544-554. https://doi.org/10.1016/j.brat.2011. 06.003

Mezzacappa, E. (2004). Alerting, orienting, and executive attention: Developmental properties and sociodemographic correlates in an epidemiological sample of young, urban children. Child Development, 75(5), 1373-1386. https://doi.org/10.1111/j. 1467-8624.2004.00746.x

Michel, F., \& Anderson, M. (2009). Using the antisaccade task to investigate the relationship between the development of inhibition and the development of intelligence. Developmental Science, 12, 272-288. https://doi.org/10.1111/j.1467-7687.2008. 00759.x

Mischel, W., \& Ayduk, O. (2002). Self-regulation in a cognitiveaffective personality system: Attentional control in the service of the self. Self and Identity, 1(2), 113-120. https://doi.org/10. 1080/152988602317319285

Miyake, A., \& Friedman, N. P. (2012). The nature and organization of individual differences in executive functions: Four general conclusions. Current Directions in Psychological Science, 21, 8-14. https://doi.org/10.1177/0963721411429458

Miyake, A., Friedman, N. P., Emerson, M. J., Witzki, A. H., Howerter, A., \& Wager, T. D. (2000). The unity and diversity of executive functions and their contributions to complex "frontal lobe" tasks: A latent variable analysis. Cognitive Psychology, 41, 49-100. https://doi.org/10.1006/cogp.1999.0734

Muthén, L. K. \& Muthén, B. O. (1998-2012). Mplus user's guide. 7. Los Angeles, CA, Muthén \& Muthén.

Nęcka, E., Gruszka, A., Orzechowski, J., Nowak, M., \& Wójcik, N. (2018). The (In)significance of executive functions for the trait of self-control: A psychometric study. Frontiers in Psychology, 9, 1139. https://doi.org/10.3389/fpsyg.2018.01139

Nigg, J. T. (2000). On inhibition/disinhibition in developmental psychopathology: Views from cognitive and personality psychology and a working inhibition taxonomy. Psychological Bulletin, 126, 220-246. https://doi.org/10.1037/0033-2909.126.2.220

Noble, K. G., Norman, M. F., \& Farah, M. J. (2005). Neurocognitive correlates of socioeconomic status in kindergarten children.
Developmental Science, 8, 74-87. https://doi.org/10.1111/j. 1467-7687.2005.00394.x

Paap, K., Anders-Jefferson, R., Zimiga, B., Mason, L., \& Mikulinsky, R. (2020). Interference scores have inadequate concurrent and convergent validity: Should we stop using the flanker, Simon, and spatial Stroop tasks? Cognitive Research: Principles and Implications, 5, 7. https://doi.org/10.1186/s41235-020-0207-y

Pastor, D. A., Barron, K. E., Miller, B. J., \& Davis, S. L. (2007). A latent profile analysis of college students' achievement goal orientation. Contemporary Educational Psychology, 32(1), 8-47. https://doi.org/10.1016/j.cedpsych.2006.10.003

Prencipe, A., Kesek, A., Cohen, J., Lamm, C., Lewis, M. C., \& Zelazo, P. D. (2011). Development of hot and cool executive function during the transition to adolescence. Journal of Experimental Child Psychology, 108, 621-637. https://doi.org/ 10.1016/j.jecp.2010.09.008

Quiroga, M. A., Hernández, J. M., Rubio, V., Shih, P. C., \& Santacreu, J. (2007). Influence of impulsivity-reflexivity when testing dynamic spatial ability: Sex and g differences. The Spanish Journal of Psychology, 10, 294-302. https://doi.org/10.1017/ S1138741600006569

Rau, H. K., Suchy, Y., Butner, J. E., \& Williams, P. G. (2016). Latent profiles of executive functioning in healthy young adults: Evidence of individual differences in hemispheric asymmetry. Psychological Research Psychologische Forschung, 80(6), 997-1019. https://doi.org/10.1007/s00426-015-0706-5

Rey-Mermet, A., Gade, M., \& Oberauer, K. (2017). Should we stop thinking about inhibition? Searching for individual and age differences in inhibition ability. Journal of Experimental Psychology, 44, 501-526. https://doi.org/10.1037/xlm0000450

Roberts, R. J., Hager, L. D., \& Heron, C. (1994). Prefrontal cognitive processes: Working memory and inhibition in the antisaccade task. Journal of Experimental Psychology: General, 123, 374-393. https://doi.org/10.1037/0096-3445.123.4.374.68

Romer, D., Betancourt, L., Giannetta, J. M., Brodsky, N. L., Farah, M., \& Hurt, H. (2009). Executive cognitive functions and impulsivity as correlates of risk taking and problem behavior in preadolescents. Neuropsychologia, 47, 2916-2926. https:// doi.org/10.1016/j.neuropsychologia.2009.06.019

Romens, S. E., \& Pollak, S. D. (2012). Emotion regulation predicts attention bias in maltreated children at-risk for depression. Journal of Child Psychology and Psychiatry, 53, 120-127. https://doi.org/10.1111/j.1469-7610.2011.02474.x

Rothbart, M. K., Ellis, L. K., Rueda, M. R., \& Posner, M. I. (2003). Developing mechanisms of effortful control. Journal of Personality, 71, 1113-1143. https://doi.org/10.1111/1467-6494. 7106009

Rothbart, M. K., Sheese, B. E., \& Posner, M. I. (2007). Executive attention and effortful control: Linking temperament, brain networks, and genes. Child Development Perspectives, 1, 2-7. https://doi.org/10.1111/j.1750-8606.2007.00002.x

Saunders, B., Milyavskaya, M., Etz, A., Randles, D., \& Inzlicht, M. (2017). Reported self-control is not meaningfully associated with inhibition-related executive function: A Bayesian analysis. Collabra Psychology, 4(1), 39. https://doi.org/10.31234/osf.io/ bxfsu

Schiller, B., Gianotti, L. R. R., Nash, K., \& Knoch, D. (2014). individual differences in inhibitory control: Relationship between baseline activation in lateral PFC and an electrophysiological index of response inhibition cerebral. Cortex, 24, 2430-2435. https://doi.org/10.1093/cercor/bht095

Schweizer, S., Gotlib, I. H., \& Blakemore, S.-J. (2020). The role of affective control in emotion regulation during adolescence. Emotion, 20(1), 80-86. https://doi.org/10.1037/emo0000695

Soloff, P. H., Price, J. C., Mason, N. S., Becker, C., \& Meltzer, C. C. (2010). Gender, personality, and serotonin-2A receptor binding 
in healthy subjects. Psychiatry Research, 181(1), 77-84. https:// doi.org/10.1016/j.pscychresns.2009.08.007

Somerville, L. H., Hare, T., \& Casey, B. J. (2011). Frontostriatal maturation predicts cognitive control failure to appetitive cues in adolescents. Journal of Cognitive Neuroscience, 23, 2123 2134. https://doi.org/10.1162/jocn.2010.21572

Stahl, C., Voss, A., Schmitz, F., Nuszbaum, M., Tuescher, O., Lieb, K., \& Klauer, K. (2014). Behavioral components of impulsivity. Journal of Experimental Psychology: General., 143, 850-886. https://doi.org/10.1037/a0033981

Toplak, M. E., West, R. F., \& Stanovich, K. E. (2013). Practitioner Review: Do performance-based measures and ratings of executive function assess the same construct. Journal of Child Psychology and Psychiatry, 54(2), 131-143. https://doi.org/10. 1111/jcpp.12001

Tottenham, N., Hare, T. A., \& Casey, B. J. (2011). Behavioral assessment of emotion discrimination, emotion regulation, and cognitive control in childhood, adolescence, and adulthood. Frontiers in Psychology, 2, 39. https://doi.org/10.3389/fpsyg.2011.00039

Traverso, L., Fontana, M., Usai, M. C., \& Passolunghi, M. C. (2018). Response inhibition and interference suppression in individuals with down syndrome compared to typically developing children. Frontiers in Psychology, 9, 660. https://doi.org/10.3389/fpsyg. 2018.00660

Vitaro, F., Ferland, F., Jacques, C., \& Ladouceur, R. (1998). Gambling, substance use, and impulsivity during adolescence. Psychology of Addictive Behaviors, 12, 185-194. https://doi.org/ 10.1037/0893-164X.12.3.185

Wallace, J., Bachorowski, J. A., \& Newman, J. P. (1991). Failures of response modulation: Impulsive behavior in anxious and impulsive individuals. Journal of Research in Personality, 25, 23-44. https://doi.org/10.1016/0092-6566(91)90003-9

Zelazo, P. D., \& Müller, U. (2002). Executive function in typical and atypical development. In U. Goswami (Ed.), Handbook of Children Cognitive Development (pp. 445-469). Blackwell.

Publisher's Note Springer Nature remains neutral with regard to jurisdictional claims in published maps and institutional affiliations. 